\title{
Development of the main and accessory placentae in the Japanese long-fingered bat, Miniopterus schreibersii fuliginosus*
}

\author{
K. Kimura $†$ and T. A. Uchida \\ Zoological Laboratory, Faculty of Agriculture, Kyushu University 46-06, Fukuoka 812, Japan
}

\begin{abstract}
Summary. The placentae of the Japanese long-fingered bat were characterized by their morphological and functional transition from the main placenta to the accessory placentae. The main placenta transformed from an endotheliodichorial to a haemodichorial (one layer of syncytiotrophoblast and one layer of cytotrophoblast cells) condition. Degeneration of the main placenta was accompanied by development of two accessory placentae. These developed on both sides (fetal side) of the main placenta, and subsequently converted from a haemodichorial (two layers of cytotrophoblast cells) to a haemomonochorial condition.
\end{abstract}

\section{Introduction}

In Japanese long-fingered bats (Miniopterus schreibersii fuliginosus), copulation, ovulation and fertilization occur in quick succession in autumn (Mōri \& Uchida, 1980, 1981a, b). Early development is followed by delayed implantation both before and after the beginning of hibernation, and subsequent development is retarded after implantation during the hibernation period (Kimura \& Uchida, 1983). Embryonic development, however, proceeds rapidly after arousal from hibernation, and the young are born in late June or early July about 260 days after fertilization (Uchida, 1957). These bats are also unusual in that they have a discoidal main placenta and/or two accessory placentae during the gestation period (Gopalakrishna \& Karim, 1980). It has been shown histologically that the accessory placentae develop as a small circular mass on each side of the main placenta (Branca, 1927; Kempermann, 1929) and they gradually grow as pregnancy progresses and eventually replace the involuted main placenta (Richardson, 1977). However, there have been few ultrastructural studies on the placentae of these bats, except for the report of Malassine (1970) on the accessory placentae from pregnant individuals with an embryo of 20-22 mm crown-rump length. The present study was therefore carried out to examine with the electron microscope the development of the placentae and their functional transition in Japanese longfingered bats.

\section{Materials and Methods}

Eleven gravid long-fingered bats ( $M$. s. fuliginosus) were captured at Ohse-do Cave $\left(32.5^{\circ} \mathrm{N}\right)$ in the Kumamoto Prefecture at evening in May-July 1978 and April-June 1980. The presumed age of

\footnotetext{
* Reprint requests to Professor T. A. Uchida.

†Present address: Laboratory of Animal Reproduction, Faculty of Textile Science and Technology, Shinshu University, Ueda 386, Japan.
} 
each embryo in days was estimated as described by Kimura \& Uchida (1983) (see Table 1). Within $24 \mathrm{~h}$ after capture, the placentae were removed under ether anaesthesia, and cut into small pieces in a mixture of $3 \%$ glutaraldehyde and $1 \%$ paraformaldehyde in $0.1 \mathrm{M}$-phosphate buffer $(\mathrm{pH} 7 \cdot 3)$, and the tissue pieces were fixed with the same fixative for $4-5 \mathrm{~h}$, then rinsed thoroughly with the same buffer and further post-fixed in cold $1.3 \% \mathrm{OsO}_{4}$ buffered with the same buffer for $1 \mathrm{~h}$, dehydrated with alcohol and embedded in Epon 812 after replacing alcohol with acetone. Thin sections $(\sim 60$ $\mathrm{nm}$ ) were doubly stained with uranyl acetate and lead citrate before examination in an Hitachi HS-9 electron microscope $(75 \mathrm{kV})$. Thick sections $(1.5 \mu \mathrm{m})$ for light microscopy were stained with toluidine blue.

\section{Results}

The development of the placentae was morphologically divided into the following stages-main placenta stage, transition stage from the main placenta to the accessory placentae, and accessory placenta stage (Table 1).

\section{Main placenta stage}

In Bat 6 pregnant with an embryo at the primitive streak stage (presumed age $\sim 182$ days), although a main placenta was not grossly visible, trophoblastic tubules had been formed antimesometrially and adjacent to the decidua basalis at the main placental region (Pl. 1, Fig. 1, inset). The walls of the trophoblastic tubules consisted of a luminal layer of syncytiotrophoblast and an underlying basal layer of cytotrophoblastic cells; the maternal blood vessels seen in the tubules still had prominent endothelial cells. A thick acellular lamina, formed, at least in part, by the maternal endothelial cell basal lamina, separated the maternal endothelium from the syncytiotrophoblast. This is the 'interstitial membrane' of other bat placentae. The early chorioallantoic placenta was therefore principally endotheliodichorial. In some regions, maternal endothelial cells had been already lost adjacent to the free surface of the syncytiotrophoblast, and peduncular and

Table 1. Development of the placentae in Japanese long-fingered bats

\begin{tabular}{|c|c|c|c|c|c|c|c|}
\hline \multirow[b]{2}{*}{ Date captured } & \multirow[b]{2}{*}{ Bat } & \multicolumn{2}{|c|}{ Main placenta } & \multicolumn{2}{|c|}{ Accessory placenta } & \multirow{2}{*}{$\begin{array}{c}\text { Stage or } \\
\text { size }^{\dagger} \\
\text { of embryo }\end{array}$} & \multirow{2}{*}{$\begin{array}{c}\text { Presumed age } \\
\text { of embryo } \\
\text { (days) } \ddagger\end{array}$} \\
\hline & & Type & Function* & Type & Function* & & \\
\hline \multicolumn{8}{|c|}{ Main placenta stage } \\
\hline 14 April 1980 & 6 & $\begin{array}{l}\text { Mainly endo- } \\
\text { theliodichorial }\end{array}$ & + & Not yet & - & $\begin{array}{c}\text { Primitive } \\
\text { streak }\end{array}$ & 182 \\
\hline 14 April 1980 & 7 & $\begin{array}{l}\text { Mainly haemo- } \\
\text { dichorial }\end{array}$ & + & formed & - & $7 \mathrm{~mm}$ & 182 \\
\hline \multicolumn{8}{|l|}{ Transition stage } \\
\hline 8 May 1978 & 1,2 & Haemo- & + & Haemo- & \pm & $12 \mathrm{~mm}$ & 206 \\
\hline 13 May 1980 & 8 & dichorial & + & dichorial & \pm & $12 \mathrm{~mm}$ & 211 \\
\hline 13 May 1980 & 9,10 & & \pm & . & $\overline{+}$ & $15 \mathrm{~mm}$ & 211 \\
\hline \multicolumn{8}{|c|}{ Accessory placenta stage } \\
\hline 6 June 1978 & 3 & Degenerated & - & Haemo- & + & $25 \mathrm{~mm}$ & 235 \\
\hline 16 June 1980 & 11 & & - & monochorial & + & $25 \mathrm{~mm}$ & 245 \\
\hline 4 July 1978 & 4,5 & & - & & + & $32 \mathrm{~mm}$ & 263 \\
\hline
\end{tabular}

* Determined according to the presence or absence of maternal blood in the trophoblastic tubules. + , functional; \pm , partly functional; - , non-functional.

† Shown by crown-rump length.

$\ddagger$ Counted from the presumed day (15 October) of ovulation and fertilization to fixation on the day after capture. 
infundibuliform cytoplasmic projections, relatively devoid of organelles, with fimbriated tips protruded from the syncytiotrophoblast into the maternal blood space, representing a partial haemodichorial relationship. These projections linked to one another all round; consequently acellular and homogeneous 'intrasyncytial laminae' arranged in an intermittent ring were formed around the maternal blood space. The syncytiotrophoblast was characterized by well developed rough endoplasmic reticulum which lay perpendicular to the luminal surface of the tubules (PI. 1, Fig. 1).

The cytotrophoblast cells were attached to the basal surface of the syncytiotrophoblast by interdigitations and desmosomes, and contained more free ribosomes and electron-dense lipid droplets than did the latter. Although the cytotrophoblast cells were joined together by desmosomes, large intercellular spaces were sometimes observed. Fetal capillaries were adjacent to the basal lamina of the cytotrophoblast cells, within the fetal mesenchyme (P1. 1, Fig. 1).

In Bat 7 with a $7-\mathrm{mm}$ embryo ( $\sim 182$ days), although the contour of a main placenta was not sharply defined, the formation of the labyrinthine placenta (principally haemodichorial) was proceeding (Pl. 1, Fig. 2).

\section{Transition stage}

Three bats with a 12-mm embryo (Bats 1 and $2 \sim 206$ days, Bat $8 \sim 211$ days) had a main placenta $(\sim 5 \mathrm{~mm} \times \sim 9 \mathrm{~mm})$ and also a small circular accessory placenta (Bats 1 and $2 \sim 2.5 \mathrm{~mm}$ diam., Bat $8 \sim 3 \mathrm{~mm}$ diam.) on both sides (fetal side) of the main placenta (Pl. 1, Fig. 3; Text-fig. 1).

In the main placenta, nearly all the endothelial cells of the maternal blood vessels had disappeared (haemodichorial), and the prominent cytoplasmic projections of the syncytiotrophoblast extended into the maternal blood space. In both types of trophoblast large lipid droplets became copious, and the intercellular spaces amongst the cytotrophoblast cells decreased in size

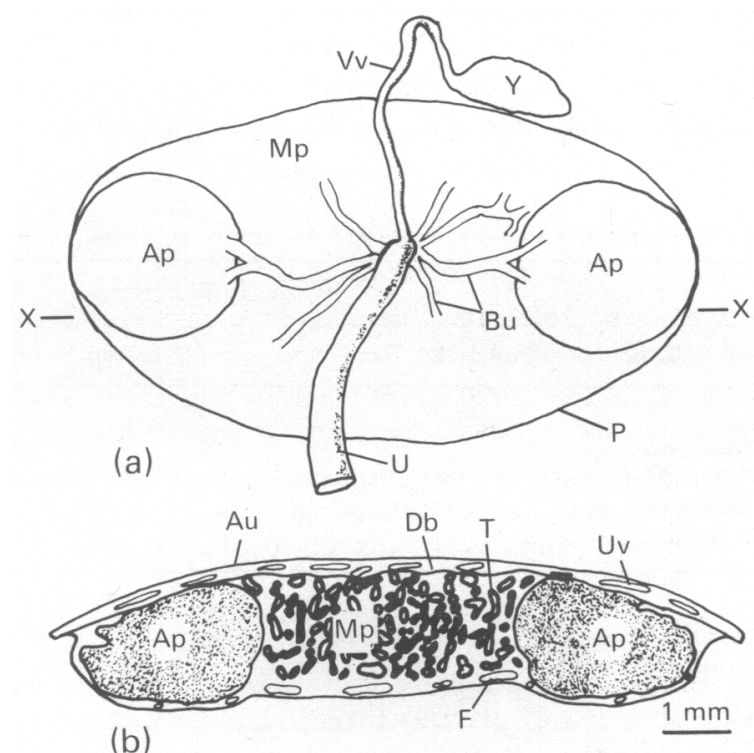

Text-fig. 1. Diagrams representing the anatomical orientation of a main placenta and two accessory placentae at the transition stage in a long-fingered bat (Bat 1). (a) Gross appearance viewed from the fetal side and (b) appearance of a horizontal section at the level indicated by $\mathrm{X}-\mathrm{X}$ in (a). Abbreviations: Ap, accessory placenta; $\mathrm{Au}$, antimesometrial uterine wall; $\mathrm{Bu}$, branch of umbilical blood vessels; $\mathrm{Db}$, decidua basalis; $\mathrm{F}$, fetal blood vessels; $\mathrm{Mp}$, main placenta; $\mathrm{P}$, placental pad; $\mathrm{T}$, trophoblastic tubule; Uv, uterine blood vessels; $\mathrm{Vv}$, vitelline blood vessels; $\mathrm{U}$, umbilical cord; $\mathrm{Y}$, yolk sac. 
and number. The fetal capillaries indented the base of the cytotrophoblastic layer and were separated from it only by the thin basal lamina in some places (Pl. 1, Fig. 4).

In the accessory placenta, masses of the cytotrophoblast cells had spread to the fetal mesenchyme (Pl. 2, Fig. 5, inset). There were two kinds of cytotrophoblast cells in these masses, i.e. the luminal surface cell and the basal cell, contributing to the wall of the early trophoblastic tubules. Although the luminal surface cells containing well developed rough endoplasmic reticulum adhered closely to one another by tight junctions, narrow lumina, which appear to be precursors of the maternal blood space but lacking the endothelium (haemodichorial), were sporadically recognized amongst the cells with some microvilli on the free surface facing the lumina. Intercellular spaces filled with homogeneous substance which is similar in density to the 'intrasyncytial lamina' were observed at irregular intervals between the basal and luminal surface cells. The basal cells were also connected to one another by desmosomes, and their basal laminae were apposed to the endothelial cells of the fetal capillaries through the fetal mesenchymal cells (Pl. 2, Fig. 5).

In some places where the formation of the trophoblastic tubules was slightly advanced, the luminal surface cells had increased amounts of free ribosomes, while the basal cells became

\section{PLATES $1-4$}

Abbreviations: Al, acellular lamina; Ap, accessory placenta; Bl, basal lamina; Bt, basal cell of trophoblastic tubule; $\mathrm{Cc}$, cell of cytotrophoblast; $\mathrm{Cm}$, cell of mesenchyme; $\mathrm{Cp}$, cytoplasmic projection of syncytiotrophoblast cell; Cs, cell of syncytiotrophoblast; $\mathrm{D}$, desmosome; $\mathrm{Db}$, decidua basalis; Ec, endothelial cell; Fb, fetal blood cell; Fc, fetal capillary; H, homogeneous substance; I, intrasyncytial lamina; Ij, intermediate junction; Is, intercellular space; L, lipid droplet; Lb, lysosomal body; Lt, luminal surface cell of trophoblastic tubule; $\mathbf{M}$, mitochondrion; Mb, maternal blood cell; Me, mesenchyme; Mp, main placenta; Ms, maternal blood space; $\mathrm{Mv}$, microvilli; $\mathrm{N}$, nucleus; Re, rough endoplasmic reticulum; $\mathrm{T}$, trophoblastic tubule; $\mathrm{Tj}$, tight junction; $\mathrm{U}$, umbilical cord; $\mathrm{V}$, vacuole.

\section{PLATE 1}

Fig. 1. Electron micrograph of a trophoblastic tubule in a main placenta at the early stage of labyrinth formation (principally endotheliodichorial), consisting of a luminal layer of syncytiotrophoblast and an underlying basal layer of cytotrophoblast. Note prominent endothelial cells in the maternal capillary and cytoplasmic projections of the syncytiotrophoblast directly facing the maternal blood space (Bat 6). Inset: light micrograph of the tubules formed antimesometrially and adjacent to the decidua basalis.

Fig. 2. Light micrograph of a part of a main placenta (principally haemodichorial) at the more advanced stage of labyrinth formation (Bat 7).

Fig. 3. External appearance of a placental pad at the transition stage, showing a small circular accessory placenta on each side of a discoidal main placenta (Bat 2).

Fig. 4. Electron micrograph of a trophoblastic tubule in a main placenta (haemodichorial) at the transition stage, showing prominent cytoplasmic projections of the syncytiotrophoblast in the maternal blood flow and indentations of the cytotrophoblastic layer by the fetal capillaries (Bat 8).

\section{PLATE 2}

Fig. 5. Electron micrograph showing a mass of cytotrophoblast cells, which are forming a trophoblastic tubule, in an accessory placenta (haemodichorial) at the transition stage. Note the cytological similarity between the luminal surface cells and the basal cells, and a precursor of the maternal blood space (Bat 1). Inset $:$ light micrograph of the early tubules spreading to the fetal mesenchyme in the accessory placenta.

Fig. 6. Electron micrograph showing a slightly advanced trophoblastic tubule in an accessory placenta at the transition stage. Note the difference between the luminal surface cells with abundant free ribosomes and the basal cells with numerous vacuoles, and expansion of the maternal blood space (Bat 8). Inset : an intermediate junction, at higher magnification, between the two layers of cytotrophoblast. 
PLATE 1

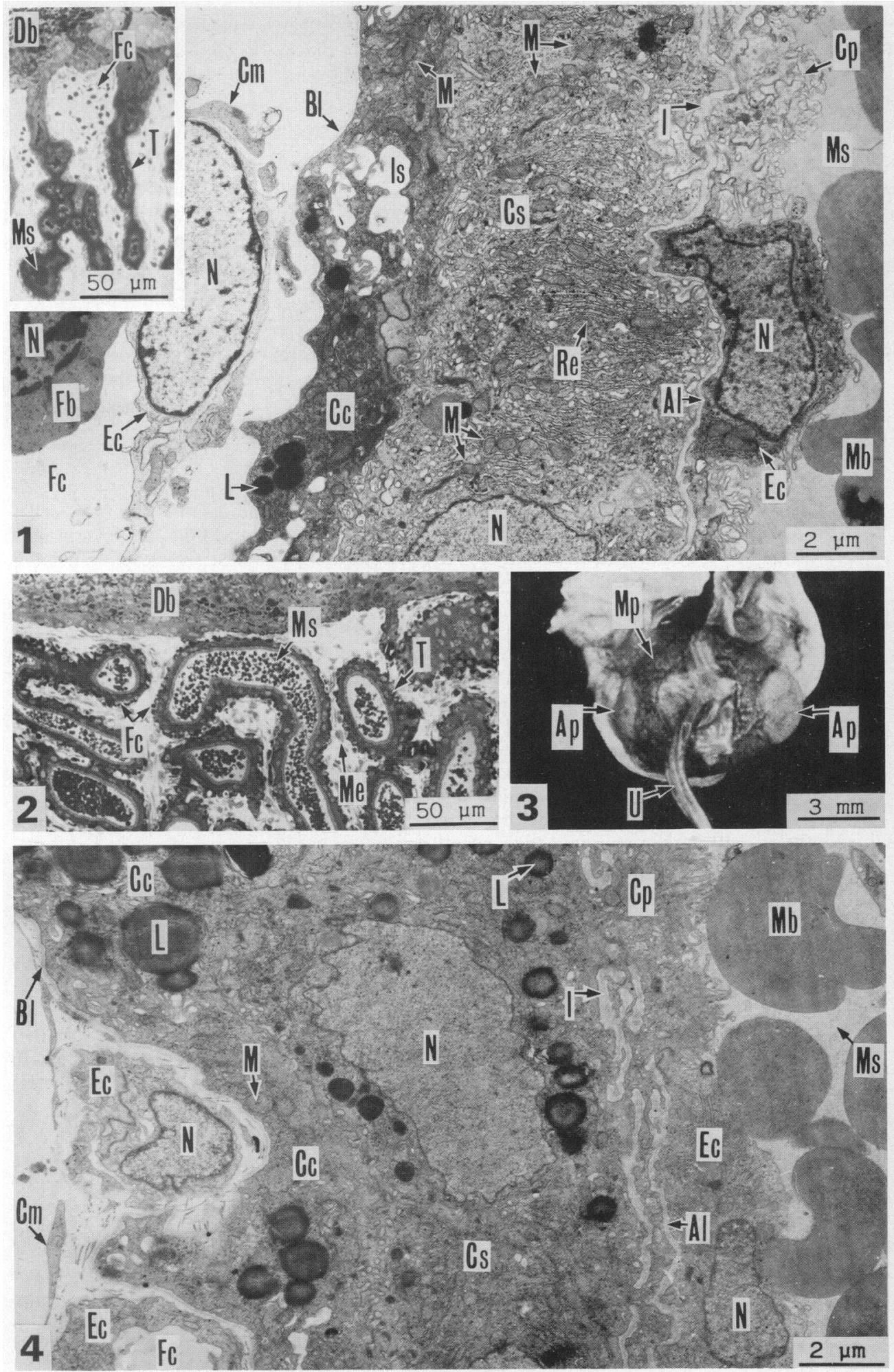

(Facing p. 122) 
PLATE 2
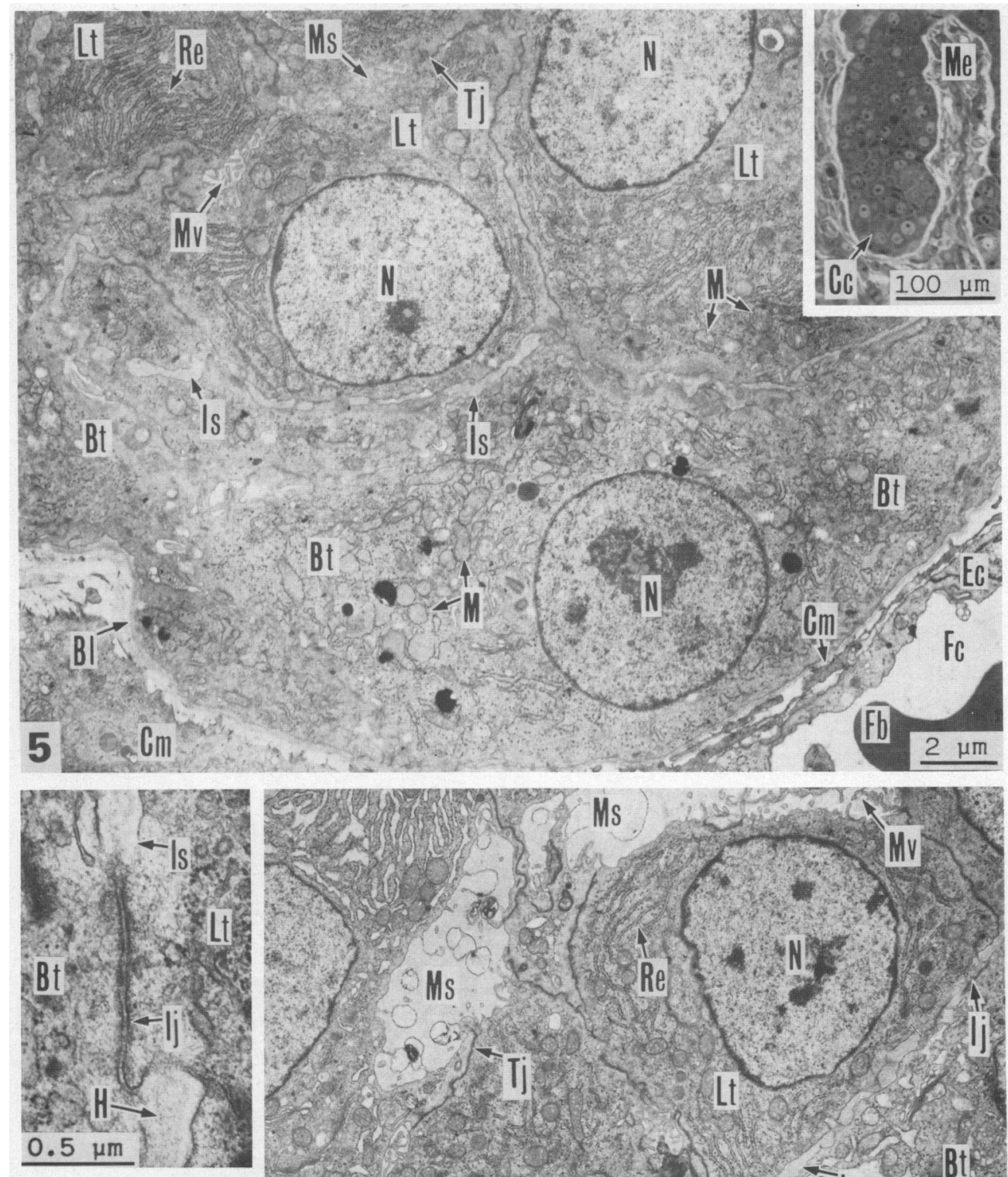

Lt $195 \mathrm{Lt}$.
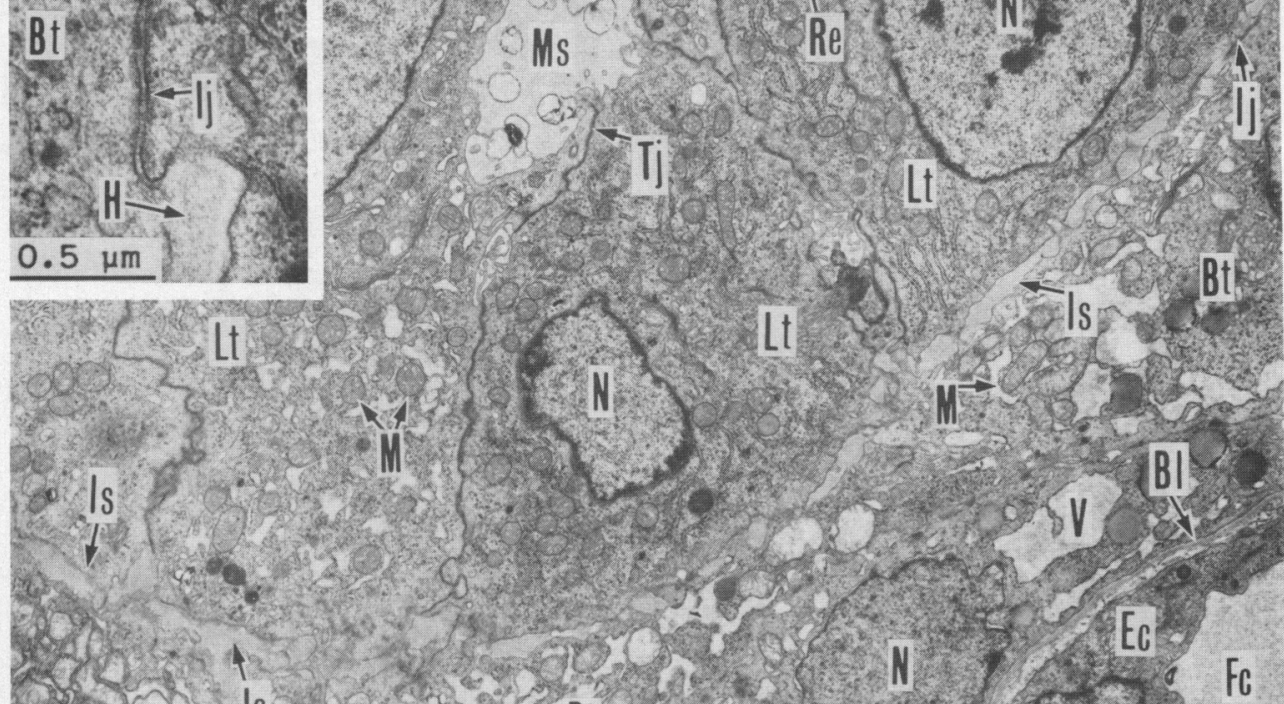

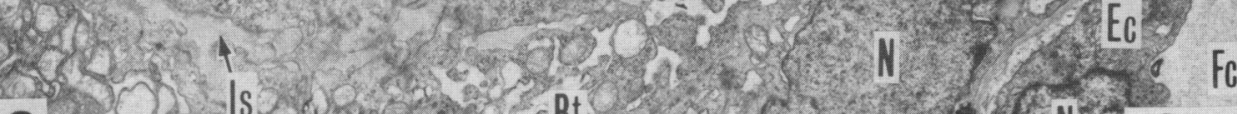
6 . 1 . 
PLATE 3
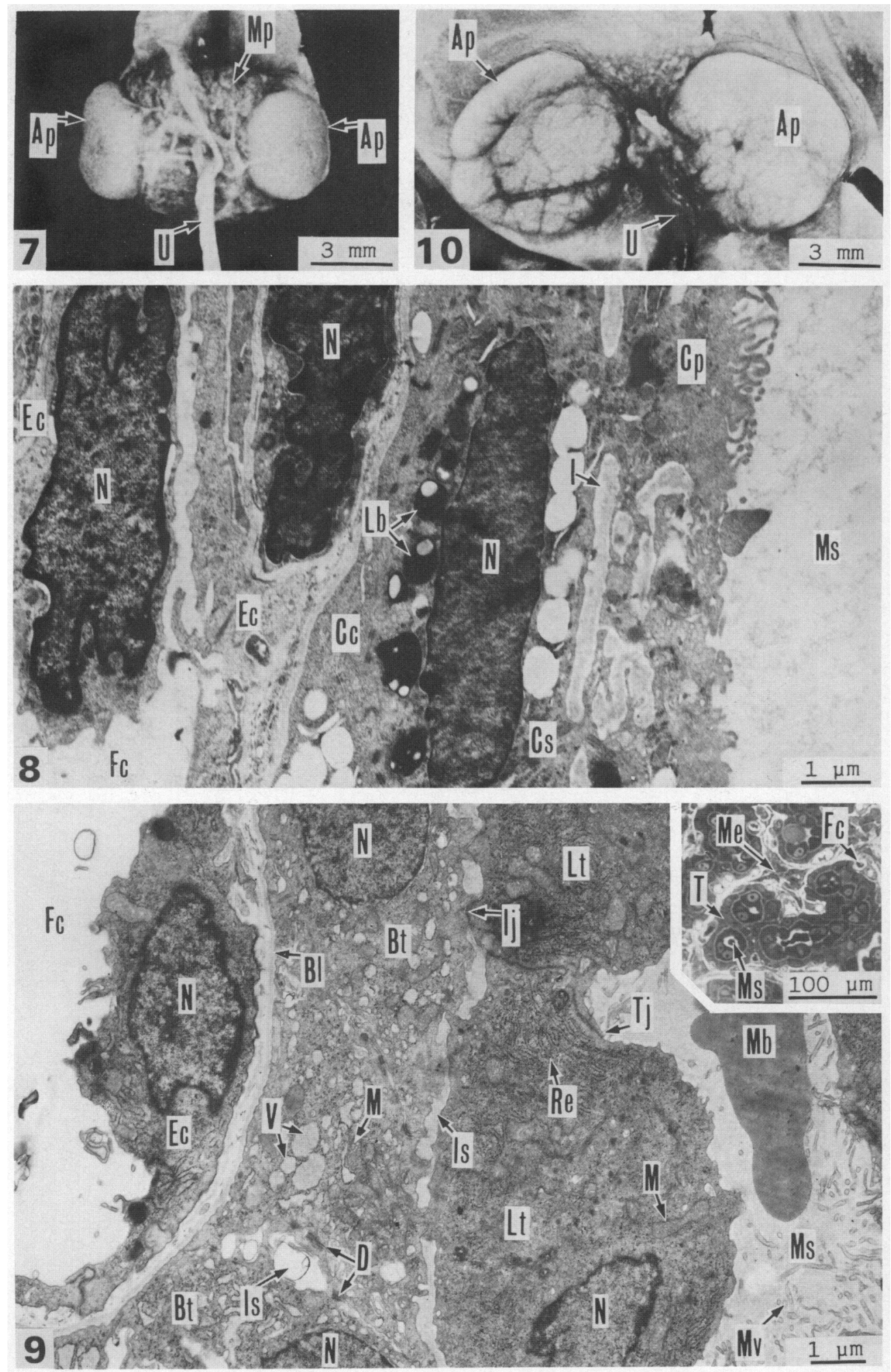
PLATE 4
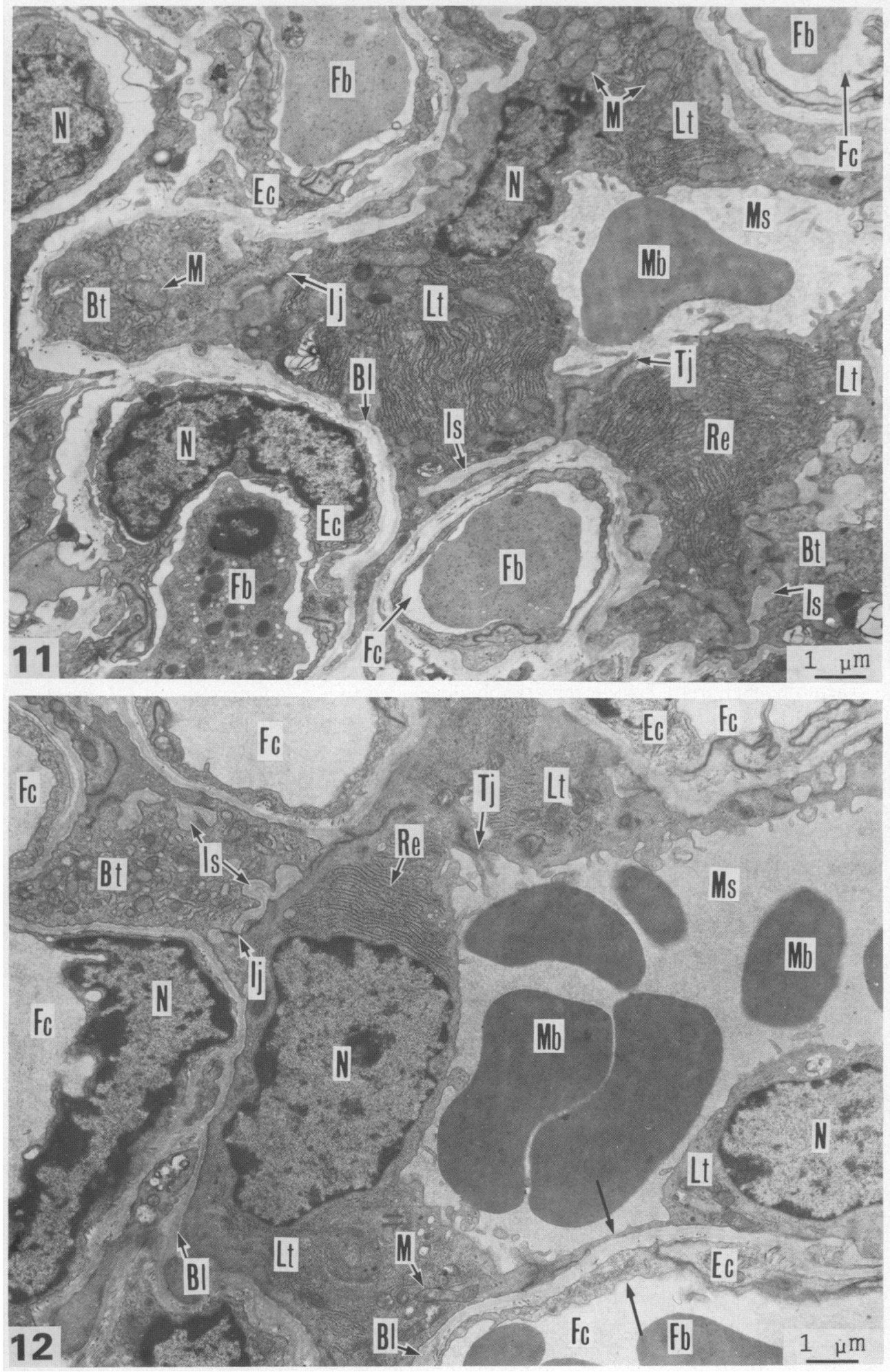
vacuolated; the two layers of cytotrophoblast connecting with each other by the so-called intermediate junctions, in the regions where the homogeneous interstitial substance does not separate them (Pl. 2, Fig. 6 and inset). The expanded maternal blood space contained a few blood cells (although none present in Pl. 2, Fig. 6).

Bats 9 and 10, each with a 15-mm embryo ( $~ 211$ days), both possessed accessory placentae at a further stage of development (diam. $\sim 4 \mathrm{~mm})$ (Pl. 3, Fig. 7). In the main placenta $(\sim 7 \mathrm{~mm} \times \sim 12$ $\mathrm{mm}$ ), most cells of the syncytiotrophoblast and the cytotrophoblast of the trophoblastic tubules had begun to necrose (Pl. 3, Fig. 8), but the maternal blood spaces still locally contained some blood cells. In the accessory placentae the trophoblastic tubules were completed in almost all regions (Pl. 3, Fig. 9, inset). Numerous blood cells appeared in the maternal blood spaces. The cytological disparity between the luminal cells and the basal cells of the tubule became conspicuous, i.e. the luminal cells which were bathed with maternal blood contained extremely electron-dense cytoplasm with well developed rough endoplasmic reticulum, while the basal cells had only slightly electron-dense cytoplasm with numerous vacuoles. At this stage, the intercellular spaces between the two cytotrophoblastic cell layers, filled with homogeneous substance, became displaced into an almost complete ring separating them into each layer. The fetal capillaries abutted onto the basal lamina of the basal cells, thus bypassing the mesenchyme (PI. 3, Fig. 9).

\section{Accessory placenta stage}

In Bats 3 and 11 each with a $25-\mathrm{mm}$ embryo ( $\sim 235$ and $\sim 245$ days respectively), the two accessory placentae, of slightly irregular shape (diam. $\sim 7 \mathrm{~mm}$ ), had reached full size and the main placenta had degenerated (Pl. 3, Fig. 10). In the accessory placentae, the maternal blood spaces in the trophoblastic tubules were more expanded, and since the basal cells had disappeared in most parts of the tubule walls, the walls were reduced to a single layer of luminal surface cytotrophoblast cells (haemomonochorial), rich in remarkably developed rough endoplasmic reticulum, and thus the endothelial cells of the fetal capillaries became adjoined to the luminal surface cells through their apposed basal laminae (Pl. 4, Fig. 11).

In the accessory placentae of Bats 4 and 5 , each with a 32-mm embryo ( $\sim 263$ days) nearly at

\section{PLATE 3}

Fig. 7. External appearance of a placental pad at the more advanced transition stage, showing more developed accessory placentae and a degenerating main placenta (Bat 10).

Fig. 8. Electron micrograph of a trophoblastic tubule in a main placenta at the same stage as in Fig. 7, showing the degenerating syncytiotrophoblast and cytotrophoblast cells (Bat 9).

Fig. 9. Electron micrograph of a trophoblastic tubule in an accessory placenta at the same stage as in Fig. 7. Note the presence of the blood cells in the maternal blood space and the juxtaposition of the fetal capillary with the basal lamina of the cytotrophoblastic basal cells (Bat 9). Inset: light micrograph of the tubules.

Fig. 10. External appearance of a placental pad at the accessory plancenta stage, showing fullsized accessory placentae and complete degeneration of a main placenta (Bat 3 ).

\section{PLATE 4}

Fig. 11. Electron micrograph showing a trophoblastic tubule in an accessory placenta (haemomonochorial) at the accessory placenta stage. Most of the tubule wall is formed of a single layer of cytotrophoblastic luminal surface cells because the basal cells have disappeared (Bat 11).

Fig. 12. Electron micrograph showing a cytotrophoblastic tubule in an accessory placenta of Bat 5 with an embryo nearly at term. Note the thinning of the placental barrier (arrows) and the complicated rearrangement between the tubule involving the maternal blood space and fetal capillaries. 
term, the trophoblastic tubules involving the more dilated maternal blood space were extensively surrounded by the fetal capillaries. At some places the luminal surface cells were extremely flattened, and the placental barrier was composed only of the attenuated trophoblast, the apposed basal laminae and the thin fetal endothelial cells (Pl. 4, Fig. 12).

\section{Discussion}

Histological observations on the placenta have been carried out in many species of bats (see Gopalakrishna \& Karim, 1979). Although a villous syndesmochorial placenta on the maternal border of the main placenta (placental pad) has been described as an accessory placenta which consists essentially of simple sparsely vascularized projections of the membranous chorion and functions during approximately the middle third of pregnancy in the brown bat, Myotis lucifugus lucifugus (Wimsatt, 1945) and the false vampire, Megaderma lyra lyra (Gopalakrishna \& Khaparde, 1978), it differs entirely from the accessory placentae of long-fingered bats in these respects. The placenta shows an extreme variety of form in different orders of mammals (Amoroso, 1961; Perry, 1981), and the bi-discoidal condition of the placenta occurs commonly in tupaiids (Luckett, 1968), cebids and cercopithecids (Benirschke \& Miller, 1982), and abnormally in man (Hamilton \& Mossman, 1972). Nevertheless, the placentae of long-fingered bats are unusual in their morphological and functional transition from the main to the accessory placental stage.

In long-fingered bats, the localization of steroid biosynthesis in the syncytiotrophoblast of the main placenta (Fonda \& Peyre, 1965) and in the 'maternal endothelial' cells (Fonda \& Peyre, 1965; Peyre \& Malassine, 1969), which are actually the luminal surface cells of the cytotrophoblast of the accessory placenta, has been demonstrated. The occurrence of much rough endoplasmic reticulum in the above cells of both placentae (present study) indicates the synthesis of protein hormones, as suggested by Malassine (1970) for the 'maternal endothelial' cell (luminal surface cytotrophoblast cells) of the accessory placenta.

In long-fingered bats, the layer closest to the maternal blood in the labyrinthine main placenta has been interpreted as an enucleate and flattened maternal endothelium (Branca, 1927) or as a specialized region of the syncytiotrophoblast (Kempermann, 1929). Electron microscopy in this study revealed that the surface consists of cytoplasmic projections of the syncytiotrophoblast, under which discontinuous intrasyncytial laminae are formed. Consequently, the placenta is essentially haemodichorial. The fine structure of the interhaemal barrier in the main placenta of these bats resembled that in the common placenta of the brown bat, Myotis l. lucifugus (Enders \& Wimsatt, 1968), the vampire bat, Desmodus rotundus murinus (Björkman \& Wimsatt, 1968) and the California bat, Macrotus californicus (Bodley, 1974), although it differed slightly from them in detail. The cytoplasmic projections appear to have the effect of increasing the surface area of the syncytiotrophoblast directly facing the maternal blood flow.

In the accessory placenta of long-fingered bats, the layer nearest to the maternal blood in the trophoblastic tubules has been regarded as a maternal endothelium, and thus the placenta has been classified as an endotheliochorial type (Branca, 1927; Kempermann, 1929; Malassine, 1970). However, our ultrastructural observations indicate that the tubule consists of two layers of cytotrophoblast cells, i.e. the luminal surface and basal cell layers, and that the so-called maternal endothelium in the tubule corresponds to the luminal surface cell layer. At the early stage before labyrinth formation, almost no differences of cytological features were recognized in the two kinds of cells from the two layers, but subsequently a homogeneous and intermittent ring, i.e. "interstitial membrane' appeared between the two layers, and they were connected to each other by intermediate junctions at places. As gestation progressed most cells of the basal layer disappeared, and the wall of the tubule became composed of only luminal surface cytotrophoblast cells. A series of these findings strongly supports the belief that the trophoblastic tubule in the accessory placenta of the long-fingered bat is made up entirely of cytotrophoblast. Such formation of the placental 
tubule, in which the maternal endothelium does not take part, has been found in the free-tailed bat, Tadarida brasiliensis cynocephala, although the interhaemal membrane in the common placenta of this bat consists of a single layer of the cellular trophoblast from the beginning of its formation, and has a thin and smooth luminal cytoplasmic layer around the maternal blood space and an intracellular intermittent ring of homogeneous material (Stephens, 1969).

Bats of the genus Miniopterus (Miniopterinae, Vespertilionidae) are distinct in their functional morphology for flight (Vaughan, 1970; Yoon \& Uchida, 1983) and in their reproductive pattern (Wimsatt, 1979; van der Merwe, 1982; Kimura \& Uchida, 1983; present study) from other vespertilionids so far examined.

According to the Enders' (1965) system of classification of placentae, we conclude that the main placenta of Japanese long-fingered bats transforms from the endotheliodichorial type to the haemodichorial type, consisting of a layer of syncytiotrophoblast and of cytotrophoblast. The accessory placenta converts from the haemodichorial type, composed of two layers of cytotrophoblast, to the haemomonochorial type formed of a single layer of the cytotrophoblast.

We thank Dr T. Mōri of our Laboratory for technical advice; Professor E. W. Jameson, Jr, Department of Zoology, University of California, for comments on the manuscript; Professor T. Yamamoto, Faculty of Medicine, Kyushu University, for valuable suggestions; and Professor A. Takeda, Faculty of Textile Science and Technology, Shinshu University, for continuous encouragement.

\section{References}

Amoroso, E.C. (1961) Placentation. In Marshall's Physiology of Reproduction, 3rd edn, Vol. 2, pp. 127-311. Ed. A. S. Parkes. Longmans, London.

Benirschke, K. \& Miller, C.J. (1982) Anatomical and functional differences in the placenta of primates. Biol. Reprod. 26, 29-53.

Björkman, N.H. \& Wimsatt, W.A. (1968) The allantoic placenta of the vampire bat (Desmodus rotundus murinus): a reinterpretation of its structure based on electron microscopic observations. Anat. Rec. 162, 83-97.

Bodley, H.D. (1974) Ultrastructural development of the chorioallantoic placental barrier in the bat, Macrotus waterhousii. Anat. Rec. 180, 351-368.

Branca, A. (1927) Recherches sur la placentation des Chiroptères. Arch. Zool. exp. gén. 66, 291-450.

Enders, A.C. (1965) A comparative study of the fine structure of the trophoblast in several hemochorial placentas. Am. J. Anat. 116, 29-68.

Enders, A.C. \& Wimsatt, W.A. (1968) Formation and structure of the hemodichorial chorio-allantoic placenta of the bat (Myotis lucifugus lucifugus). Am.J. Anat. 122, 453-490.

Fonda, E. \& Peyre, A. (1965) Localisation de la $\Delta-5.3-\beta-$ hydroxystéroid-déshydrogénase dans le placenta de Minioptère (Chiroptére) au cours de la gestation. C.r. hebd. Séanc. Acad. Sci., Paris 261, 2963-2964.

Gopalakrishna, A. \& Karim, K.B. (1979) Fetal membranes and placentation in Chiroptera. J. Reprod. Fert. 56, 417-429.

Gopalakrishna, A. \& Karim, K.B. (1980) Female genital anatomy and the morphogenesis of foetal membranes of Chiroptera and their bearing on the phylogenetic relationships of the group. In Nat. Acad. Sci., India: Golden Jubilee Comm. Vol., pp. 379-428.
Gopalakrishna, A. \& Khaparde, M.S. (1978) Development of the foetal membranes and placentation in the Indian false vampire bat, Megaderma lyra lyra (Geoffroy). Proc. Indian Acad. Sci. 87B, 179194

Hamilton, W.J. \& Mossman, H.W. (Eds) (1972) The implantation of the blastocyst and the development of the fetal membranes, placenta and decidua. In Human Embryology, 4th edn, pp. 83-161. Macmillan Press, London.

Kempermann, C.T. (1929) Die Placenta der Fledermaus Miniopterus schreibersii und ihre funktionelle Bedeutung. Z. Anat. EntwGesch. Berl. 91, 292-303.

Kimura, K. \& Uchida, T.A. (1983) Ultrastructural observations of delayed implantation in the Japanese long-fingered bat, Miniopterus schreibersii fuliginosus. J. Reprod. Fert. 69, 187-193.

Luckett, W.P. (1968) Morphogenesis of the placenta and fetal membranes of the tree shrews (Family Tupaiidae). Am. J. Anat. 123, 385-428.

Malassine, A. (1970) Etude histologique et ultrastructurale du disque placentaire de Minioptère, Miniopterus schreibersi (Chiroptère): sa nature endothéliochoriale, son caractère endocrine. Archs Anat microsc. Morph. exp. 59, 99-112.

Mori, T. \& Uchida, T.A. (1980) Sperm storage in the reproductive tract of the female Japanese longfingered bat, Miniopterus schreibersii fuliginosus. $J$. Reprod. Fert. 58, 429-433.

Mōri, T. \& Uchida, T.A. (1981a) Ultrastructural observations of fertilization in the Japanese long-fingered bat, Miniopterus schreibersii fuliginosus. J. Reprod. Fert. 63, 231-235.

Möri, T. \& Uchida, T.A. (1981 b) Ultrastructural observations of ovulation in the Japanese long-fingered bat, 
Miniopterus schreibersii fuliginosus. J. Reprod. Fert. 63, 391-395.

Perry, J.S. (1981) The mammalian fetal membranes. $J$. Reprod. Fert. 62, 321-335.

Peyre, A. \& Malassine, A. (1969) L'équipement stéroidodeshydrogénasique et la fonction endocrine du placenta de Minioptère (Chiroptère). C. r. Séanc. Soc. Biol. 163, 914-917.

Richardson, E.G. (1977) The biology and evolution of the reproductive cycle of Miniopterus schreibersii and $M$. australis (Chiroptera: Vespertilionidae). J. Zool. Lond. 183, 353-375.

Stephens, R.J. (1969) The development and fine structure of the allantoic placental barrier in the bat Tadarida brasiliensis cynocephala. J. Ultrastruct. Res. 28, 371-398.

Uchida, T.A. (1957) Fertilization and hibernation in bats. Heredity, Tokyo 11, 14-17. (In Japanese.) van der Merwe, M. (1982) Histological study of implantation in the Natal clinging bat (Miniopterus schreibersii natalensis). J. Reprod. Fert. 65, 319-323.

Vaughan, T.A. (1970) Flight pattern and aerodynamics. In Biology of Bats, Vol. I, pp. 195-216. Ed. W. A. Wimsatt. Academic Press, New York.

Wimsatt, W.A. (1945) The placentation of a vespertilionid bat, Myotis lucifugus lucifugus. Am. J. Anat. 77, $1-51$.

Wimsatt, W.A. (1979) Reproductive asymmetry and unilateral pregnancy in Chiroptera. J. Reprod. Fert. 56, 345-357.

Yoon, M.H. \& Uchida, T.A. (1983) Identification of recent bats belonging to the Vespertilionidae by the humeral characters. J. Fac. Agr., Kyushu Univ. 28, 3150 .

Received 19 August 1983 